\title{
Photodegradation of Atorvastatin under Light Conditions Relevant to Natural Waters and Photoproducts Toxicity Assessment
}

\author{
Šárka Klementová, Pavla Petráňová, Pavla Fojtíková \\ Faculty of Science, University of South Bohemia, České Budějovice, Czech Republic \\ Email: sklement@jcu.cz
}

How to cite this paper: Klementová, Š., Petráňová, P. and Fojtíková, P. (2021) Photodegradation of Atorvastatin under Light Conditions Relevant to Natural Waters and Photoproducts Toxicity Assessment. Open Journal of Applied Sciences, 11, 489-499. https://doi.org/10.4236/ojapps.2021.114035

Received: March 16, 2021

Accepted: April 22, 2021

Published: April 25, 2021

Copyright $\odot 2021$ by author(s) and Scientific Research Publishing Inc. This work is licensed under the Creative Commons Attribution International License (CC BY 4.0).

http://creativecommons.org/licenses/by/4.0/

\begin{abstract}
Atorvastatin, widely prescribed hypolipidemic drug, undergoes rapid, probably self-sensitised, degradation (less than $20 \%$ left after 25 -minute irradiation) if irradiated by wavelengths $300-350 \mathrm{~nm}$ in aqueous solution. When ferric ions are added to the reaction mixture, the degradation follows first order kinetics with a rate constant of $0.130 \mathrm{~min}^{-1}$. Photochemical degradation may thus represent a significant way of environmental transformation of this pharmaceutical. Toxicity testing of atorvastatin and atorvastatin photoproducts performed on the water plant Lemna minor revealed that atorvastatin itself exhibited no observable toxic effect measured as leaf area growth inhibition, while the photoproducts showed a significant toxicity to the plant, which shows the extreme importance of investigating not only toxicity of drugs themselves on aquatic organisms but also effects of their transformation products.
\end{abstract}

\section{Keywords}

Atoravastatin, Photodegradation, Atorvastatin and Photoproducts Toxicity, Lemna minor

\section{Introduction}

Pharmaceuticals for human use have recently received much attention as emerging organic micropollutants in the aquatic environment [1] [2] [3] [4] [5]. These compounds enter the aquatic environment via waste-water treatment plants as a result of the incomplete removal of these compounds from hospital and manufacturing plant effluents and domestic wastewater.

The effort of developers and manufacturers is focused on the stability of 
pharmaceuticals to prolong their shelf-life. Thus these compounds are in most cases resistant to hydrolysis and biodegradation, and a photoinitiated degradation represents possible transformation pathways in the aquatic environment. Photoinitiated reactions in sunlit surface waters can proceed as 1) direct photodegradation (with compounds absorbing high-energy solar radiation reaching the Earth's surface), 2) indirect reactions mediated by photochemically formed intermediates such as hydroxyl and other radicals, singlet oxygen, aquated electrons [1] [6] [7] or 3) photocatalysed reactions in which the active forms of catalysts are formed photochemically [2].

Atorvastatin is a member of the group known as statins, antilipidemic drugs that lower the level of cholesterol in the blood by reducing cholesterol production by the liver [8]. Statins belong to the most widely prescribed drugs in developed countries and have been detected in natural waters worldwide in concentrations ranging from $10 \mathrm{ng} / \mathrm{l}$ to $1500 \mathrm{ng} / \mathrm{l}$ [9] [10] [11] [12]. Their photochemical degradation has been studied by several scientific groups. Lam \& Mabury [1] Lam et al. [13] and Wang et al. [14] studied the influence of dissolved organic matter and some inorganic ions on atorvastatin photochemical degradation, while Razavi et al. [7] and Wang et al. [15] investigated the effect of reactive oxygen species on the photodegradation of atorvastatin.

The presence of statins in natural surface waters provoked studies on their possible toxicity to water organisms such as fish [16] [17], mussels [18], or crustaceans [19].

The objective of this study was firstly to investigate the photocatalytic role of ferric ions in the photoinitiated transformation of atorvastatin and secondly to test the toxicity of atorvastatin itself and its photoproducts on the water plant Lemna minor. The motivation for the study was the fact that toxicity of drugs repeatedly detected in the aquatic environment is investigated but there is an absolute lack of information about toxic effects of compounds formed during the transformation of the drugs in the aquatic environment.

\section{Materials and Methods}

Atorvastatin (more than 99.9\%) was purchased from Merck (Germany), $\mathrm{FeCl}_{3}$ and $\mathrm{HCl}$ (both p.a.) from Lachema (Czech Rep.). Milli- ${ }^{\circledR}$ water was used for the dissolution of chemicals.

Irradiation: Samples containing $3 \mathrm{ml}$ of the atorvastatin solution in 1-cm glass cuvettes with PTFE lids were irradiated in a Rayonet reactor with RPR $3000 \AA$ lamps emitting light at a wavelength range of $254-350 \mathrm{~nm}$, light below $300 \mathrm{~nm}$ was filtered out by optical glass to imitate the short-wavelength solar radiation that reaches the Earth's surface. Experimental apparatis used for irradiation is illustrated in Figure 1. Radiant flux was measured using a Lutron UV A light metre, the total power of all of the electromagnetic radiation within the wavelength range 320 - $390 \mathrm{~nm}$ (the range detected by the Lutron metre) emitted per unit time was calculated for the irradiated area, the value being $4.5 \mathrm{~W}$. 


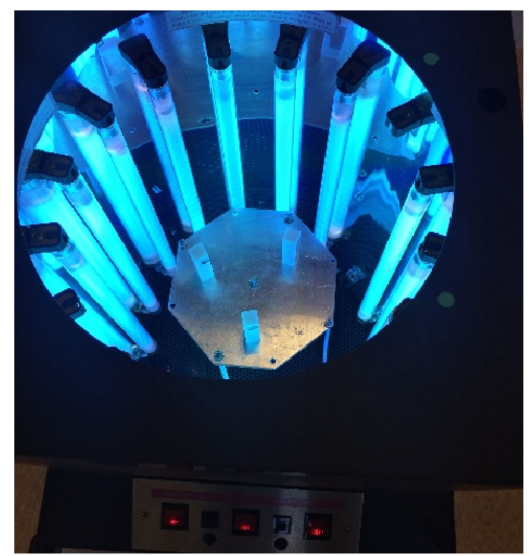

Figure 1. Irradiation of samples in Rayonet reactor with RPR $3000 \AA$ lamp. The cuvettes with irradiated samples were placed on an aluminium stand at a height in the middle of the lamps length. Behind the lamps, there is a lining of burnished aluminium serving as a reflecting mirror.

Analyses of samples: The extent of atorvastatin photodegradation was determined by HPLC (ThermoScientific Dionex Ultimate systém 3000 (USA), column Phenomenex Kinetex $5 \mathrm{~mm}$ EVO C18, $30 \times 2.1 \mathrm{~mm}$, mobile phase water with $0.001 \% \mathrm{HCOOH}$ and acetonitrile 0.6:0.4 (v/v) with PDA 3000RS spectrophotometric and FLD 3000RS fluorescence detectors.

The extent of ferric ions reduction during irradiation was determined spectrophotometrically using 1, 10-phenantroline as a complexing agent for ferrous ions.

A Lemna sp. growth inhibition test was performed according to the OECD Guideline [20] using the vascular plant Lemna minor which was obtained from a natural water reservoir in Netolice in the southern part of Czech Rep. (GPS coordinates $\left.49^{\circ} 02^{\prime} 53^{\prime \prime} \mathrm{N} ; 14^{\circ} 12^{\prime} 30^{\prime \prime} \mathrm{E}\right)$. Prior to testing, the plants were cultivated in Swedish Standard Lemna sp. growth medium (SIS) prepared accordingly to OECD (2002) for 3 weeks. To test the effect of atorvastatin on the Lemna growth, a concentration series of $0,25,50,100$ and $200 \mathrm{mg} / \mathrm{l}$ was prepared in SIS medium. All growth inhibition tests were performed in opened glass crystallising dishes $(\varnothing 9 \mathrm{~cm})$, under natural daylight and at $23^{\circ} \mathrm{C}$ temperature for seven days. Colonies consisting of cca 10 fronds (leaf surface area approx. $1 \mathrm{~cm}^{2}$ ) were exposed to the concentration series of atorvastatin; each concentration treatment was carried out in 4 replicates. The total frond area was measured using the Easy Leaf Area software [21]. To test the effect of photoproducts, a mixture of photodegradation products (irradiated sample, irradiation time 15 minutes) was diluted to provide the final concentration of remaining atorvastatin of the same value as was its highest concentration in atorvastatin toxicity test, i.e. of 200 $\mathrm{mg} / \mathrm{l}$. Experimental arrangement for toxicity test is schematically shown in Figure 2. As illustrated in the scheme in Figure 2, the dishes with individual concentrations were distributed in a way to minimise systemic error based on position relative to the light source (window). 


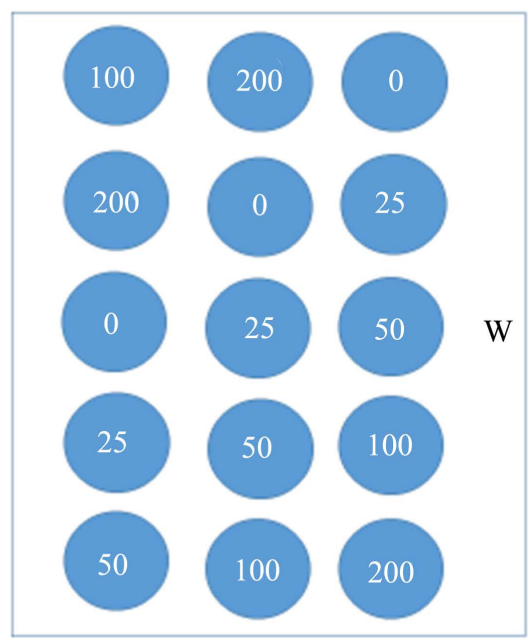

(a)

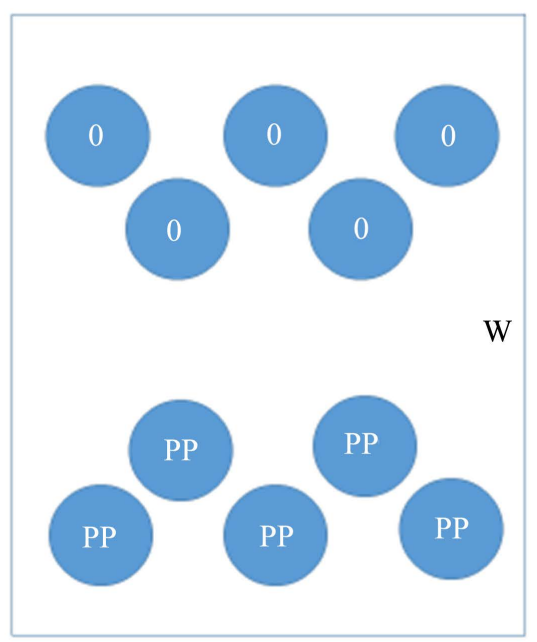

(b)

Figure 2. Experimental arrangement of toxicity test. (a) Atorvastatin toxicity test: blue circles represent individual crystallizing dishes, numbers give the concentration of atorvastatin; (b) Photoproduct test: blue circles represents individual crystallizing dishes, upper rows are control dishes (zero concentration of photoproducts), lower rows are dishes with photoproducts (PP). W shows where light source (window) was placed.

Differences between samples were evaluated using 2-way analysis of variance followed by Tukey post-hoc test; $\mathrm{p}$-values less than 0.05 are considered significant.

\section{Results}

The absorption spectra of atorvastatin itself and of a complex of atorvastatin with ferric ions are shown in Figure 3. As can be seen from the absorption spectra, the atorvastatin absorption of radiation above $300 \mathrm{~nm}$ is very small. The addition of ferric ions results in the formation of a complex with a significantly higher absorbance in the UV region, namely with considerable light absorption in the region of wavelengths longer than $300 \mathrm{~nm}$.

The photochemical degradation of atorvastatin is demonstrated in Figure 4. The figure illustrates that the degradation proceeds even for atorvastatin itself when no ferric ions are added, and that the degradation is rapid-more than $80 \%$ of the original amount is transformed after 25 -minute irradiation. Nevertheless, the atorvastatin degradation in this case is slow in the first minutes of irradiation, the reaction rate significantly increasing after 10 minutes of irradiation. The reaction does not follow first order kinetics. With lower concentrations of added ferric ions $(1.7 \mathrm{mg} / \mathrm{l}$ and $3.4 \mathrm{mg} / \mathrm{l})$, the first slower stage of the reaction is gradually less pronounced but still noticeable. In the presence of the highest tested concentration of added ferric ions, $5 \mathrm{mg} / \mathrm{l}$, the reaction follows first order kinetics with a rate constant of $0.130 \mathrm{~min}^{-1}$. The concentration of added ferric ions did not dramatically affect the remaining amounts of atorvastatin after a 25 -minute irradiation which where $13 \%, 9 \%, 7 \%$, and $4 \%$ of the original amount for $0,1.7,3.4$, and $5 \mathrm{mg} / \mathrm{l}$, resp. What was remarkably influenced by the presence 


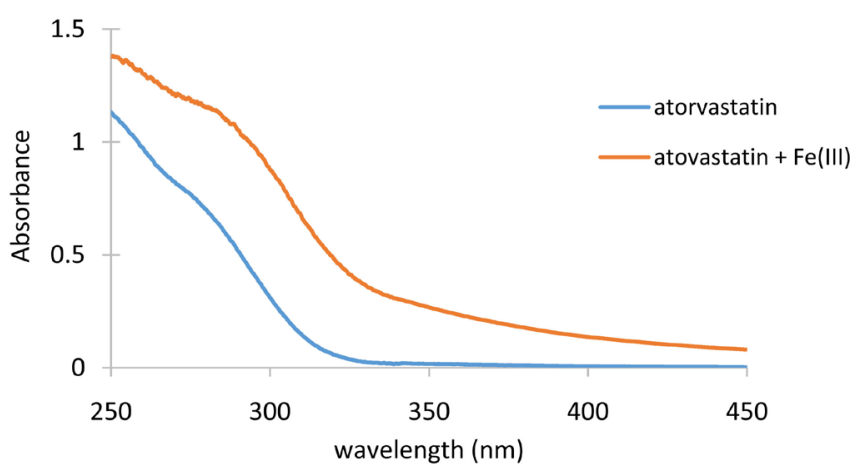

Figure 3. Absorption spectra of atorvastatin and atorvastatin with ferric ions. Concentration of atorvastatin $36 \mathrm{mg} / \mathrm{l}$, concentration of Fe (III) $5 \mathrm{mg} / \mathrm{l}$.

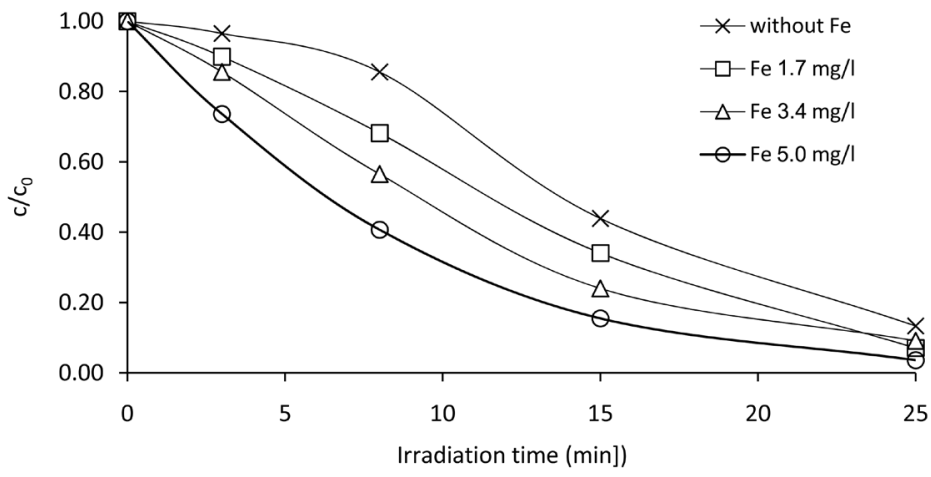

Figure 4. Dependence of atorvastatin degradation on the concentration of ferric ions added to the reaction mixture.

of ferric ions was product formation-in the presence of ferric ions significantly greater amounts of products were formed, as illustrated in Figure 5. Figure 5 shows the chromatograms received with fluorescent detector where peak of atorvastatin itself (at the retention time $6.7 \mathrm{~min}$.) is rather small. On the other hand, products of photochemical degradation had low UV absorption but their fluorescent signals were significant. Therefore, for evaluation of atorvastatin decay, UV detection was applied while photoproduct formation was detected using fluorescence signal. Nevertheless, as can be seen from Figure 5, if Fe (III) is present in the reaction mixture, even atorvastatin exhibits higher fluorescence. The two products formed in the reaction mixture where only atorvastatin was present (peaks with retention times 9.5 and 10.3) were formed as well in the presence of Fe (III), the presence of Fe (III) caused a formation of many more products.

The testing of the photochemical reduction of ferric ions in irradiated reaction mixture with $5 \mathrm{mg} / \mathrm{l} \mathrm{Fe}$ (III) revealed that after 1 minute of irradiation, approximately $6 \%$ of added ferric ions were reduced to ferrous ones, the amount did not rise during further irradiation.

The toxicity testing of atorvastatin on Lemna minor was performed with the concentration of $0,25,50,100$, and $202 \mathrm{mg} / \mathrm{l}$ of atorvastatin. The percentage of increase in leaf area after a 7-day period incubation is illustrated in Figure 6. 

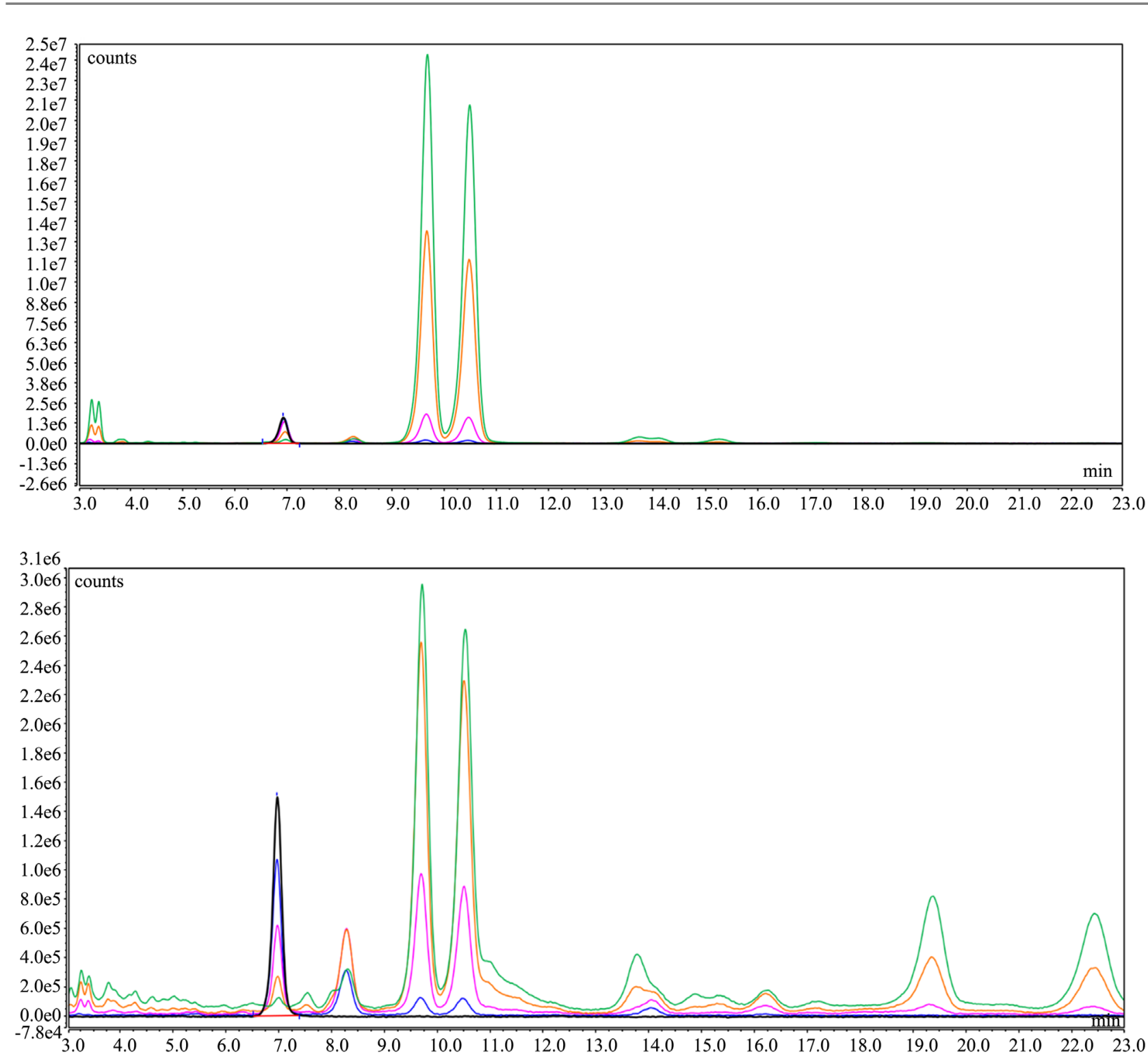

Figure 5. Comparison of the number of products formed during irradiation: upper part-atorvastatin without added Fe (III); lower part-atorvastatin $+5 \mathrm{mg} / \mathrm{l} \mathrm{Fe}$. Black-before irradiation; blue, pink, orange and green-irradiation of 3, 8, 15 and $25 \mathrm{mi}$ nutes, resp.

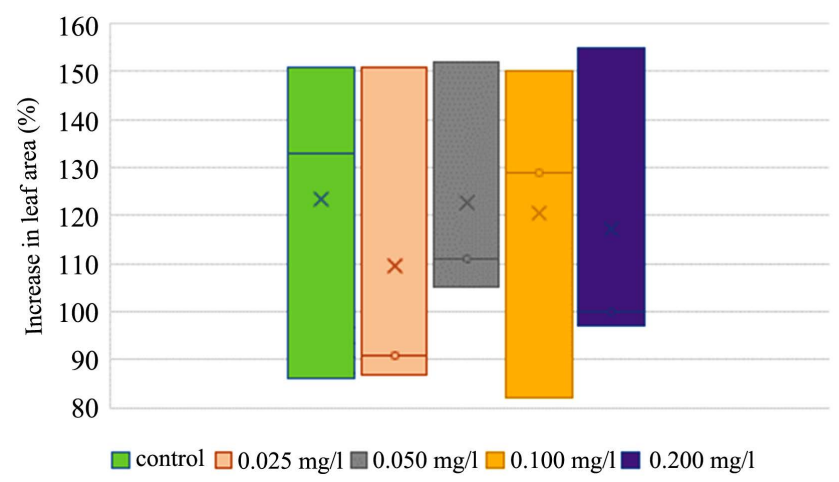

Figure 6. Lemna minor growth inhibition test-exposure to atorvastatin in concentrations of $0,25,50,100$ and $200 \mathrm{mg} / \mathrm{l}$. 


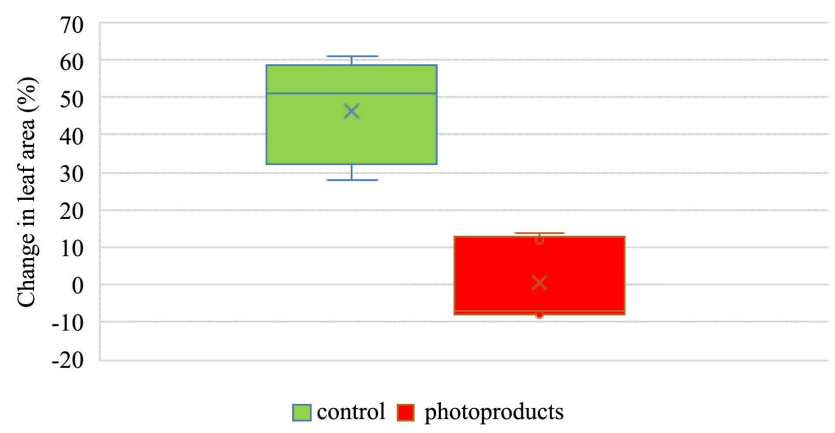

Figure 7. Lemna minor growth inhibition test-exposure to photoproducts of atorvastatine; concentration of remaining atorvastatin in the reaction mixture $200 \mathrm{mg} / \mathrm{l}$.

Though the increase in leaf areas varies within individual tested concentration, the graphical representation shows no noticeable effect on Lemna sp. growth.

The toxicity testing of the mixture of products formed during the photochemical degradation of atorvastatin is depicted in Figure 7. As can be seen from the figure, there is a significant difference between the control set and the set exposed to photoproduct mixture. In the series of five control tests, the increase in leaf area varied from $28 \%$ to $61 \%$; in the series of photoproduct tests, a small increase in two cases and even a decrease in leaf area in three cases were observed. The received value of p-parameter for the statistical comparison of the two sets of data (control vs. photoproducts) was 0.005 .

\section{Discussion}

The degradation of atorvastatin itself in this study did not proceed as first order kinetics reaction as can be seen in Figure 4, though Wang et al. [14] reported first order kinetics with a rate constant of 0.0369 hour $^{-1}$ for atorvastatin photochemical degradation in phosphate buffer. In our study, the reaction was slow in the initial stages of irradiation and its reaction rate increased gradually with increasing irradiation time. A similar observation was made with the photochemical degradation of another drug, verapamil, which is a calcium channel blocker [2]. A slow reaction at the beginning of the irradiation period is not suprising because of the low absorption of atorvastatin of the incident radiation. Since the reaction was performed in Milli- $\mathrm{Q}^{\circledR}$ water, catalysis by trace amounts of metal ions is not very likely. We therefore hypothesise that in the initial phase of photodegradation a product with photosensitising properties is formed, and that after an accumulation of the product, the reaction rate gradually increases due to a process of self-sensitisation [22]. Wang et al. [14] also suggested a possible selfsensitisation in connection with products of the photodegradation of atorvastatin with regard to the excited triplet state of atorvastatin may contribute to singlet oxygen production from the oxygen dissolved in the solution.

The relatively fast direct photochemical degradation of atorvastatin itself observed in this study (Figure 4) justifies an assumption that photochemical processes may significantly contribute to the transformation of the drug in surface waters exposed to solar radiation. 
Addition of metal, Fe (III), ions to the reaction mixure resulted in increase in initial reaction rate as illustrated in Figure 4. Wang et al. [14] also studied the effects of various additives, among them ferric ions. In their experiments, the addition of ferric ions corresponding to the lowest concentration used in our study led to an almost eightfold increase in reaction rate, the rate constant was obtained from the first-order kinetics model. In our study, the addition of ferric ions shortened the initial "lag" phase, but first-order kinetics was a suitable model only for the highest iron concentration used in the study. The observed value of $0.130 \mathrm{~min}^{-1}$ differs in order of magnitude from the values reported by Wang et al. [14]. This variance might be caused by the different wavelength range and intensity of the used radiation since Wang et al. [14] gave only the intensity at one wavelength, namely $365 \mathrm{~nm}$.

The presence of metal ions noticeably influenced the formation of products. In the reaction mixture of the atorvastatin alone, only two main products were created as demonstrated in Figure 5. In the reaction mixtures with added ferric ions, a number of other products appeared, all of them had longer retention times than atorvastatin, which means they are less polar than atorvastatin itself. Products formed in the study exhibit a significant fluorescence but they could not be detected through measuring a UV signal.

The influence of Fe (III) on photodegradation rate of atorvastatin is particularly important from environmental point of view since ferric ions are present in most surface water bodies, often abundantly, in mg/l [23]. Thus the photodegradation may provide a wide range of photoproducts as observed in this study, with consequences to toxicity (Figure 7).

As given in results, the testing of the photochemical reduction of ferric ions in irradiated reaction mixture with $5 \mathrm{mg} / \mathrm{l}$ of Fe (III) revealed that a very short (1 minute) period of irradiation is enough for reduction of nonnegligible amount of ferric ions (6\%). The longer irradiation did not affect the amount of reduced form which means that this is the steady state concentration resulting from two processes going agains each other-photochemical reduction of metal oxidised form and its reoxidation by molecular oxygen present in solution. Comparison with values reached in the photodegradation of hydrocortisone, b-estradiol, parabens [2], and verapamil [24] where the values of the ferrous ions reached $60 \%$ $70 \%$ of the added amount led us to conclude that the photoinitiated degradation of atorvastatin did not proceed via a photocatalytic mechanism in which the reduced metal species is the active catalytic form [25]; the more likely cause of the increase in reaction rates in the initial phases of photodegradation was the direct photodegradation due to enhanced light absorption by the atorvastatin-Fe complex.

The toxicity of atorvastatin on Lemna minor was not proven even for concentrations as high as $200 \mathrm{mg} / \mathrm{l}$ as demonstrated in Figure 6, though Brain et al. [26] observed a toxic effect on Lemna sp., namely Lemna gibba and determined the $\mathrm{EC}_{10}$ value to be $26 \mathrm{mg} / \mathrm{l}$. On the other hand, the toxicity of atorvastatin photoproducts was conclusively demonstrated (Figure 7) - the received p-parameter 
value of 0.005 strongly suggests that the null hypothesis on the non-toxic effect of photoproducts when compared to sets of control data is incorrect. The present study did not focus on atorvastatin products characterisation and identification and thus it cannot be concluded whether only one of the products was responsible for the toxic effect or whether it was a cumulative effect of a number of substances created by the phototransformation of atorvastatin. It would definitely be worth further investigation. It is worth mentioning that there are numerous data about toxicity of drugs on various aquatic organisms but there is a lack of knowledge of the photodegradation processes that may often (with recalcitrant molecules to which drugs belong) represent the main path of their environmental transformation. Moreover, the products of photochemical degradation may possess even more toxic capacity to aquatic organisms than the original drug themselves.

\section{Conclusions}

Despite the weak absorption of radiation of wavelengths longer than $300 \mathrm{~nm}$, atorvastatin underwent significant degradation even without catalysing or sensitising additives. The course of degradation with a "lag" phase at the beginning of the reaction and increase in rate in its latter stages is supposed to arise from a sensitising agent formation, i.e. via self-sensitisation process. The finding supports a conclusion that atorvastatin may undergo direct phototransformation in the aquatic environment.

The addition of ferric ions changed the courses of photodegradation curves shortening the initial "lag" phase. With a concentration of ferric ions of $5 \mathrm{mg} / \mathrm{l}$, the reaction followed first-order kinetics with the rate constant of $0.130 \mathrm{~min}^{-1}$. The effect of ferric ions seems to be partially connected with the enhanced absorption of radiation in the range of $300-350 \mathrm{~nm}$, partially other mechanisms may participate. Increase in atorvastatin photodegradation rate together with formation of a high number of additional product when compared to the reaction mixture without added $\mathrm{Fe}$ (III) leads to an assumption that the Fe-assisted photochemical degradation may be prevalent in atorvastatin environmental transformation. Reaction mixture of atorvastatin photoproducts formed in the presence of Fe (III) was conclusively shown to have notable toxic effect on the aquatic plant, Lemna minor. The products of atorvastatin photochemical transformation may have similar effects on other aquatic organisms as well and therefore be of high environmental significance.

\section{Acknowledgements}

The authors gratefully acknowledge the financial support of the research provided by the Faculty of Science, University of South Bohemia. Sincere thanks go to Christopher Steer for his diligent proof-reading of this paper.

\section{Conflicts of Interest}

The authors declare no conflicts of interest regarding the publication of this paper. 


\section{References}

[1] Lam, M.W. and Mabury, S.A. (2005) Photodegradation of the Pharmaceuticals Atorvastatin, Carbamazepine, Levofloxacin, and Sulfamethoxazole in Natural Waters. $A q$ uatic Sciences, 67, 177-188. https://doi.org/10.1007/s00027-004-0768-8

[2] Klementova, S., Kahoun, D., Doubkova, L., Frejlachova, K., Dusakova, M. and Zlamal, M. (2017) Catalytic Photodegradation of Pharmaceuticals-Hemogeneous and Heterogeneous Photocatalysis. Photochemical \& Photobiological Sciences, 16, 67-71. https://doi.org/10.1039/C6PP00164E

[3] Klementova, S. (2018) Photochemical Degradation of Organic Xenobiotics in Natural Waters. In: Saha, S. and Mondal, S., Eds., Photochemistry and PhotophysicsFundamentals to Applications, IntechOpen. https://doi.org/10.5772/intechopen.74756

[4] Mezzelani, M., Gorbi, S. and Regoli, F. (2018) Pharmaceuticals in the Aquatic Environments: Evidence of Emerged Threat and Future Challenges for Marine Organisms. Marine Environmental Research, 140, 41-60. https://doi.org/10.1016/j.marenvres.2018.05.001

[5] Patel, M., Kumar, R., Kishor, K., Mlsna, T., Pittman Jr., C.U. and Mohan, D. (2019) Pharmaceuticals of Emerging Concern in Aquatic Systems: Chemistry, Occurrence, Effects, and Removal Methods. Chemical Reviews, 119, 3510-3673. https://doi.org/10.1021/acs.chemrev.8b00299

[6] Tixier, C., Singer, H., Oellers, S. and Muller, S. (2003) Occurrence and Fate of Carbamazepine, Clofibric Acid, Diclofenac, Ibuprofen, Ketoprofen and Naproxen in Surface Waters. Environmental Science \& Technology, 37, 1061-1068. https://doi.org/10.1021/es025834r

[7] Razavi, B., Abdeimelek, S.B., Song, W., O’Shea, K.E. and Cooper, W.J. (2011) Photochemical Fate of Atorvastatin (Lipitor) in Simulated Natural Waters. Water Research, 45, 625-631. https://doi.org/10.1016/j.watres.2010.08.012

[8] Stancu, C. and Sima, A. (2001) Statins: Mechanism of Action and Effects. Journal of Cell Molecular Medicine, 5, 378-387. https://doi.org/10.1111/j.1582-4934.2001.tb00172.x

[9] Conley, J.M. Symes, S.J., Kindelberger, S.A. and Richards, S.M. (2008) Rapid Liquid Chromatography-Tandem Mass Spectrometry Method for the Determination of a Broad Mixture of Pharmaceuticals in Surface Water. Journal of Chromatography A, 1185, 206-215. https://doi.org/10.1016/j.chroma.2008.01.064

[10] Lee, H.B., Peart, T.E., Svoboda, M.L. and Backus, S. (2009) Occurrence and Fate of Rosuvastatin, Rosuvastatin Lactone, and Atorvastatin in Canadian Sewage and Surface Water Samples. Chemosphere, 77, 1285-1291. https://doi.org/10.1016/j.chemosphere.2009.09.068

[11] Tete, V.S., Nyoni, H., Mamba, B.B. and Msagati, T.A.M. (2020) Occurrence and Spatial Distribution of Statins, Fibrates and Their Metabolites in Aquatic Environments. Arabian Journal of Chemistry, 13, 4358-4373.

https://doi.org/10.1016/j.arabjc.2019.08.003

[12] Ministry of Agriculture of Czech Republic (2018) Report on the State of Water Management in Czech Republic. (In Czech Language)

[13] Lam, M.W., Young, C.J., Brain, R.A., Johnson, D.J., Hanson, M.A., Wilson, C.J., Richards, S.M., Solomon, K.R. and Mabury, S.A. (2004) Aquatic Persistence of Eight Pharmaceuticals in a Microcosm Study. Environmental Toxicology and Chemistry, 23, 1431-1440. https://doi.org/10.1897/03-421

[14] Wang, M., Li, J., Shi, H., Miao, D., Yang, Y. Qian, L. and Gao, S. (2018) Photolysis 
of Atorvastatin in Aquatic Environment: Influencing Factors, Products, and Pathways. Chemosphere, 212, 467-475.

https://doi.org/10.1016/j.chemosphere.2018.08.086

[15] Wang, H., Liu, P., Wang, M., Wu, X., Shi, Y., Huang, H. and Gao, S. (2021) Enhanced Phototransformation of Atorvastatin by Polystyrene Microplastics: Critical Role of Aging. Journal of Hazardous Materials, 408, 124756.

https://doi.org/10.1016/j.jhazmat.2020.124756

[16] Thorpe, J.L., Doitsidou, M., Ho, S.-Y., Raz, E. and Farber, S.A. (2004) Germ Cell Migration in Zebrafish Is Dependent on HMGCoA Reductase Activity and Prenylation. Developmental Cell, 6, 295-302.

https://doi.org/10.1016/S1534-5807(04)00032-2

[17] Ellesat, K.S., Tollefsen, K.E., Asberg, A. Thomas, K.V. and Hylland, K. (2010) Cytotoxicity of Atorvastatin and Simvastatin on Primary Rainbow Trout (Oncorhynchus mykiss). Toxicology in Vitro, 24, 1610-1618.

https://doi.org/10.1016/j.tiv.2010.06.006

[18] Falfushynska, H., Sokolov, E.P., Haider, F., Oppeermann, C. Kragl, U. Ruth, W., Stock, M., Glufke, S., Winkel, E.J. and Sokolova, I.M. (2019) Effects of a Common Pharmaceutical, Atorvasttin, on Energy Metabolism and Detoxification Mechanisms of a Marine Bivalve Mytilus edulis. Aquatic Toxicology, 208, 47-61.

https://doi.org/10.1016/j.aquatox.2018.12.022

[19] Liu, Y., Ding, R., Pan, B., Wang, L., Liu, S. and Nie, X. (2019) Simvastatin Affect the Expression of Detoxification-Related Genes and Enzymes in Daphnia Magna and Alter Its Life History Parameters. Ecotoxicology and Environmental Safety, 182, 109389. https://doi.org/10.1016/j.ecoenv.2019.109389

[20] OECD (2002) OECD Guidelines for Testing of Chemicals, Gideline 221. Lemna sp. Growth Inhibition Test.

[21] Easlon, H.M. and Bloom, A.J. (2014) Easy Leaf Area: Automated Digital Image Analysis for Rapid and Accurate Measurement of Leaf Area. Applications in Plant Sciences, 2, 1400033. https://doi.org/10.3732/apps.1400033

[22] Calzaferri, G. and Spahni, W. (1986) Self Sensitization of Photo-Chlorine Evolutionin Aqueous Dispersions of Silver Zeolites. Journal of Photochemistry, 32, 151-155. https://doi.org/10.1016/0047-2670(86)87004-6

[23] Dojlido, J.R. and Best, G.A. (1993) Inorganic Substances in Surface Waters. In: Chemistry of Water and Water Pollution, Ellis Horwood Series in Water and Wastewater Technology, Elis Horwood Limited, Chichester, 59-205.

[24] Klementová, S., Poncarová, M., Kahoun, D., Šorf, M., Dokoupilová, E. and Fojtíková, P. (2020) Toxicity Assessment of Verapamil and Its Photodegradation Products. Environmental Science and Pollution Research, 27, 35650-35660. https://doi.org/10.1007/s11356-020-09830-w

[25] Klementova, S. and Wagnerova, D.M. (1994) Photocatalytic Effect of Fe (III) on Oxidation of Two-Carbon Organic Substances Related to Natural Waters. Collection of Czechoslovak Chemical Communications, 59, 1066-1076. https://doi.org/10.1135/cccc19941066

[26] Brain, R.A., Reitsma, S.T., Lissemore, S.I., Bestari, K.J., Sibley, P.K. and Solomon, K.R. (2006) Herbicidal Effects of Statin Pharmaceuticals in Lemna gibba. Environmental Science and Technology, 40, 5116-5123. https://doi.org/10.1021/es0600274 